\title{
Sentir y pensar el duelo perinatal: acompañamiento emocional de un grupo de padres
}

\section{Feeling and thinking the perinatal mourning: emotional accompaniment by a parent group}

\author{
Ana M. López Fuentetaja ${ }^{(1)}$ y Odei Iriondo Villaverde ${ }^{(2)}$ \\ (1) Psicóloga Clínica. Hospital Universitario 12 de Octubre. Madrid. \\ (2) Psicóloga Clínica. Hospital Universitario del Sureste. Madrid.
}

\begin{abstract}
Resumen: Se presenta el recorrido de un grupo de padres en situación de duelo perinatal, llevado a cabo en el Hospital Universitario 12 de Octubre de Madrid. Esta experiencia forma parte de un Programa de Enlace acordado entre los Servicios de Neonatología y Ginecología-Obstetricia y el de Psiquiatría y Salud Mental, para la atención psicológica a padres que afrontan la muerte perinatal de su bebé, o que este presente un grave riesgo vital. La complejidad de este tipo de duelo involucra un plano real y otro simbólico, que precisa la elaboración a un nivel particular y también como pareja de padres. El trabajo en grupo de padres aporta la posibilidad de expresar y compartir los sentimientos íntimos derivados de la pérdida, en un marco de contención que facilita la elaboración del duelo.

Palabras clave: Duelo, duelo perinatal, programa de enlace, grupo de padres, apoyo emocional
\end{abstract}

\begin{abstract}
This paper presents the journey of a group of parents in a situation of perinatal mourning at the University Hospital 12 de Octubre in Madrid. This experience is part of a Hospital Liaison Program, agreed between the Departments of Neonatology and Gynecology-Obstetrics and the Department of Psychiatry and Mental Health and intended to provide psychological care to parents who are facing a perinatal death or whose baby is in a serious vital risk situation. The complexity of this type of mourning, which involves both a real and a symbolic plane, belonging to the space of the imagined, particular and unique for every mother and father, requires elaboration at individual level and also as a couple of parents. The parent group provides the possibility to express and share the intimate feelings derived from the loss within a framework of emotional containment that facilitates elaboration of mourning.

Keywords: Mourning, perinatal mourning, liaison program, parent group, emotional support.
\end{abstract}

\footnotetext{
Ana M. López Fuentetaja es Psicóloga Clínica. Hospital Universitario 12 de Octubre. Madrid. Odei Iriondo Villaverde es Psicóloga Clínica. Hospital Universitario del Sureste. Madrid.

La correspondencia sobre este artículo debe enviarse a Ana M. López Fuentetaja. E-mail: alofuen@gmail.com u Odei Iriondo Villaverde E-mail: odei.iriondo@gmail.com
}

(cc) EY-NC-ND Este es un artículo Open Access bajo la licencia CC BY-NC-ND. 
La pérdida perinatal constituye una experiencia emocionalmente devastadora para las madres, cuyo duelo se puede prolongar durante un largo periodo de tiempo y en muchas ocasiones de forma silenciosa.

En la actualidad, se está otorgando cada vez mayor importancia al reconocimiento del mismo y el sufrimiento que lleva aparejado, si bien aún queda bastante camino para otorgarle el lugar que merece a nivel sanitario y social. Con motivo de este avance, desde distintos hospitales, se están poniendo en marcha guías de actuación que pretenden atender las necesidades psicológicas derivadas de esta experiencia, así como de dotar de herramientas a los profesionales sanitarios, suponiendo un escalón más en la concienciación social.

Para poder comprender el duelo perinatal, además de conocer los aspectos específicos del mismo, se hace necesario conocer el lugar que ocupa el duelo en general en nuestra actual sociedad y también los aspectos comunes y sus procesos de elaboración, habiéndose producido diversas conceptualizaciones del mismo a lo largo del tiempo.

Podríamos decir que nuestra sociedad está viviendo de espaldas a la muerte, convirtiendo esta experiencia natural en un gran tabú, no facilitando espacios para sentir, expresar dolor y compartir. En su lugar, existe una tendencia generalizada a incitar a la persona en duelo a recuperarse rápidamente (Tizón y Sforza, 2008), tapar el llanto, seguir funcionando y rendir, en lugar de rendirse. Es decir, el duelo se inserta en una cultura que impone determinados mandatos sobre quién puede hacer un duelo, cómo, sobre quién y durante cuánto tiempo.

La elaboración de las pérdidas en general, no solo de la producida tras un fallecimiento, es inherente a nuestra existencia, siendo un hecho natural el tener que afrontarlas y aprender a convivir con ellas. Desencadenan respuestas que también se pueden considerar naturales y saludables y que nos afectan a nivel físico, emocional, intelectual, relacional, conductual y espiritual (Payás, 2014), siendo estas respuestas muy diferentes de unas personas a otras. Es decir, la universalidad de la pérdida no impide que las vivencias sean únicas a nivel personal, intersubjetivo e intercultural. Podemos decir por tanto, que el duelo representa una experiencia única, que cada persona afrontará de forma particular con sus propios recursos y que produce un sufrimiento psicológico. Se asienta en una biografía y personalidad previas y se produce en unas circunstancias determinadas y en un momento social y cultural que condicionan el proceso y su expresión.

Se hace mucho más difícil aún la capacidad de entender y manejar la muerte de forma natural cuando la pérdida obedece a sucesos demasiado alejados de lo mínimamente predecible y que son ilógicos e injustos (Bayés, 2001). Encontramos así las muertes que contravienen las leyes entre generaciones, falleciendo los hijos antes que los padres, y mucho más cuando la muerte es de un recién nacido. Estos hechos, que forman parte de nuestra existencia, bajo la presión de la ocultación y el aislamiento, producen traumas y dolor y remueven los pilares del psiquismo.

La construcción de "muros de silencio" alrededor de la muerte (Payás, 2014, p.47), como estrategia de huida desesperada del dolor emocional, dificulta la elaboración natural y saludable de este inevitable proceso del ciclo vital.

Si algo caracteriza al duelo es que se trata de un proceso único, no un estado, en el que la persona avanza por una serie orientativa de fases hacia la integración de la pérdida irreparable e insustituible y se esfuerza por aprender a seguir viviendo en un nuevo escenario, en parte, vacío.

Se trata de un proceso dinámico por naturaleza, que conlleva siempre conectar con el dolor emocional, sentirlo, expresarlo y también hacer algo con ese dolor, no solo esperar a que pase el tiempo. De hecho, algunos autores lo plantean en términos de llevar a cabo una serie de tareas, lo cual implica una actitud activa por parte de la persona en duelo, quien puede hacer algo para crecer en nuevas direcciones de forma positiva (Worden, 2004). Por ello, la elaboración no es sólo cuestión de tiempo, sino que exige un trabajo interior (Juri, 2006).

Desde los modelos psicodinámicos, la conceptualización del duelo y su resolución ha variado desde definiciones basadas primordialmente en mecanismos intrapsíquicos a otras entendidas desde modelos biopsicosociales.

Freud (1917/1993) consideraba el duelo un proceso normal, no patológico, que la persona superaría pasado un tiempo. Para ello, tendría que aceptar el principio marcado desde la realidad de que lo perdido no existiría nunca más. Junto a esto, pasado un tiempo, el Yo se dejaría llevar por las satisfacciones narcisistas otorgadas por la vida, siendo ambos aspectos los que permitirían la desligazón con el objeto perdido y su desplazamiento a uno nuevo (Freud, 1917/1993). 
Freud no sistematizó una conceptualización del duelo patológico, si bien de su lectura se puede entender como similar a la melancolía. En el duelo normal la pérdida sería consciente, mientras que en la melancolía la pérdida puede ser inconsciente o se puede saber quién se perdió, pero no qué se perdió con la persona.

M. Klein (1940/1989) trabaja con la hipótesis de que cualquier duelo reactiva otros duelos tempranos y, por ello, moviliza toda la estructura psíquica. Al igual que Freud, considera crucial el reconocimiento, la aceptación de la pérdida y el desplazamiento a otro objeto nuevo, pero añade que este proceso reavivaría la ambivalencia residual nunca elaborada respecto a nuestro objeto primigenio. Esto supondría alteraciones profundas en nuestra relación con los recuerdos inconscientes que nos vinculan a nuestras figuras significativas de cuidados (Cabodevilla, 2007). A través de la confianza progresiva en los objetos externos, puede también recuperarla y reconocer las buenas cualidades de la persona perdida. Klein recoge los aspectos positivos y creativos del duelo y aún va mucho más lejos, al considerar que el dolor causado por cualquier experiencia adversa entraña similitudes con el duelo, reactivando la posición depresiva infantil y requiriendo un trabajo mental similar al del duelo para su superación. Considera que, en el duelo normal, la persona reintroyecta tanto a la persona real perdida, como a sus padres amados a los que sintió como objetos internos buenos. Es precisamente el tener una buena imagen de la madre dentro de sí lo que ayuda a vencer esa pérdida.

Lindemann (1944) realiza observaciones de personas que perdieron trágicamente a sus familiares. Coincide con Freud en que la elaboración del duelo consistiría en retirar la energía del objeto significativo perdido para poder dedicarse a nuevas relaciones, siendo el desapego con el fallecido el trabajo central del duelo. En su descripción, aparece una conceptualización del trabajo de duelo como un proceso psicológico universal, relativamente pasivo, desencadenado por un acontecimiento que la persona no desea, produciéndose una serie de reacciones psicológicas que ella no elige, pero que serán las que permitirán la elaboración del duelo.

Kübler-Ross (1969) también describe un proceso con etapas relativamente universales, mencionando la negación, rabia, negociación, depresión y aceptación.

Worden (1982) y Rando (1984) conciben el duelo como un proceso más activo y particular, introduciendo la idea de tareas a realizar en el trabajo de duelo. Worden describe las de aceptar la realidad de la pérdida, experimentar el dolor de la pérdida, adaptarse a un medio en el que ya falta el ser querido, y retirar la energía emocional de la persona que falta, reinvirtiéndola en otras relaciones. Rando (1983) añade que habría que tener en cuenta la particularidad de cada duelo, estando esta determinada por la mezcla única de factores psicológicos, fisiológicos y sociales pertenecientes a la persona en duelo.

Bowlby $(1980,1993)$, incorpora enfoques de la psicología cognitiva y la etología, apartándose de las conceptualizaciones estrictamente psicoanalíticas. Partió de observaciones realizadas sobre las reacciones de niños de entre uno y tres años, cuando se les apartaba de la figura materna y las reacciones derivadas para recuperar el apego. Si bien, inicialmente, la respuesta es de protesta y de gran esfuerzo por recuperar a la madre, más adelante y persistiendo la ausencia de la misma, se pierde la esperanza en recuperarla, aunque el deseo de ello sí permanece. Señaló las coincidencias entre las respuestas de estos niños y las de los adultos que perdían un ser querido, refiriéndose al término de duelo como un proceso adaptativo con condicionantes sociales y psicológicas, que obliga a una definición de sí mismo y de su contexto.

Describió la "tríada de la pérdida afectiva" implicada como aflicción, desesperanza y desapego o depresión. En relación a lo anterior, identificó cuatro etapas del duelo correlacionadas, que serían: la fase de impacto y obnubilación; la fase de protesta, anhelo y búsqueda; la fase de desorganización y desesperación; y, finalmente, la fase de reorganización (Bowlby, 1961, 1980, 1993) .

Desarrolla dos variedades de duelo no concluido, que serían el duelo crónico y la ausencia prolongada de aflicción consciente, explicando ambas por la permanencia de lazos con el fallecido. La existencia de estos lazos llevaría a un impulso de búsqueda. En el duelo crónico, la persona se quedaría en la fase de añoranza y búsqueda y en la ausencia de aflicción en la fase de embotamiento (Bowlby, 1980, 1993).

Para Tizón (2004), al igual que para Bowlby, los duelos se entienden como fenómenos biopsicosociales que involucran emociones, cambios en las cogniciones y en las relaciones y que modifican o rompen ciertas formas de vinculación establecidos con anterioridad. Considera que se alteran los recuerdos, la vivencia de relaciones interiorizadas y las capacidades y expresiones yoicas que configuran el mundo interno. A pesar de esto, la ansiedad, el sufrimiento, la enfermedad y la desestructuración psicosocial que pueden formar parte de 
las primeras etapas, a medio y largo plazo, con una resolución adecuada, dan lugar a una mayor organización, integración y creatividad. La elaboración del duelo se entenderá desde esta perspectiva como el trabajo psicológico que se inicia tras la pérdida y termina con la aceptación de la realidad interna y externa (Tizón, 2004). Es precisamente la aceptación de esta realidad interna y externa lo que permite la superación de la tristeza, la posible ambivalencia hacia lo perdido, y la recomposición del mundo interno con sus cogniciones, sentimientos y fantasías fundamentales (Tizón, 2004). Describe además otros procesos psicosociales, antropológicos e incluso económicos, que están también implicados, y que se expresan de forma diferente en las diversas culturas, como las expresiones de luto, rituales, etc.

Para Tizón (2004), las personas que consiguen alcanzar una mayor tolerancia a la frustración y a la ambivalencia podrán convivir de forma más adecuada con la duda, la incertidumbre, el pesar y la culpa, sin tener que llegar a la actuación. Junto a lo anterior, la capacidad de introspección y de insight facilitará la posibilidad de contactar con la realidad interna y externa de una forma más global, lo que otorgará sentido y coherencia al momento vital. Añade que este proceso de duelo tan doloroso tendrá un final mejor si se inserta en el apoyo de la comunidad y no se patologiza.

Para Bleichmar (2010a), los acontecimientos traumáticos pueden predisponer a las personas a la reemergencia de un estado depresivo cuando las condiciones vitales actuales confrontan y evocan estados previos de impotencia/indefensión, dada la importancia de las etapas tempranas para determinar el mundo interno. Las experiencias previas traumáticas pueden haberse experimentado, entre otros, en el ámbito del bienestar personal, del sentimiento de valía, de ser agente de la propia vida, de eficacia o de proximidad con la figura de apego (Bleichmar, 2003, 2010a). A su vez, constata la implicación de diversos sistemas motivacionales (1999) en el proceso de duelo y la importancia de la estructura de personalidad básica de las personas, que va a condicionar la reacción ante los distintos tipos de pérdidas y de los síntomas predominantes. Esta aportación se acompaña de tratamientos diferenciados en el caso de presentarse un duelo patológico (Bleichmar, 2010b).

\section{La pérdida perinatal: aspectos de contextualización}

Según la Organización Mundial de la Salud (OMS), el período perinatal se extiende desde las 22 semanas de gestación hasta la primera semana de vida del neonato (World Health Organization [WHO], 2006). Sin embargo, en la práctica y en la literatura especializada se conceptualiza en términos más amplios, existiendo variabilidad entre países y organizaciones científicas.

La OMS, la Federación Internacional de Ginecología y Obstetricia (FIGO) y la Sociedad Española de Ginecología y Obstetricia (SEGO) recomiendan considerar las siguientes definiciones y criterios cronológicos (Lombardía y Fernández, 2007; Pastor Montero, 2016):

- Muerte fetal: Es la muerte del producto de la concepción antes de la expulsión o su extracción completa del cuerpo de la madre, independientemente del tiempo de duración de embarazo. Cronológicamente se divide en:

- Muerte fetal temprana: Todas las muertes desde la concepción hasta las 22 semanas de gestación y/o peso de gestación $<500$ gr. Se refiere, por tanto, a los abortos.

- Muerte fetal intermedia: Las muertes fetales que tienen lugar en las 22-28 semanas de gestación y/o peso al nacer entre 500-999 gr.

- Muerte fetal tardía: Muertes fetales a partir de las 28 semanas de gestación y/o peso al nacer > o igual a $1000 \mathrm{gr}$.

- Muerte neonatal: Es la muerte del recién nacido en las primeras 4 semanas de vida (28 días). Se divide en:

- Muerte neonatal precoz: Muerte del recién nacido en los primeros 7 días de vida.

- Muerte neonatal tardía: Muerte del neonato desde los 7 días completos hasta los 28 días completos de vida.

La tasa de mortalidad perinatal es un indicador importante de la salud pública (Flennady et al., 2016; De Bernis et al., 2016; Cassidy, 2018). Evitar la muerte perinatal es importante porque tiene impactos psicológicos y sociales para las familias y los profesionales sanitarios, además de costes económicos sustanciales (Mistry, 
Heazell, Vincent y Roberts, 2013; Heazell et al., 2016; Campbell, Kurinczuk, Heazell, Leal y Rivero-Arias, 2018; Cassidy, 2018).

A nivel epidemiológico, la tasa de mortalidad perinatal se ha reducido en España durante las últimas décadas, debido a las mejoras sanitarias y sociales (Pastor Montero, 2016). Según datos disponibles del Instituto Nacional de Estadística (INE), considerando un corte temporal retrospectivo de diez años, la mortalidad perinatal en España pasó de situarse en un 4'87 \%o en el año 2004 a un 4,46\%o en 2014. Los datos más recientes disponibles (INE, 2017) sitúan la tasa de mortalidad perinatal en un 4,53 por mil nacimientos en España (figura 1).

Tabla 1. Tasas de muerte perinatal, neonatal y mortalidad infantil en España en 2016

\begin{tabular}{lll}
\hline Nacimientos vivos & Muertes fetales tardías & Muertes neonatales (primer año) \\
\hline 391.930 & 1246 & 1120 \\
\hline $\begin{array}{l}\text { Tasa mortalidad perinatal } \\
\text { (muertes fetales y neonatales } \\
\text { precoces/total nacimientos*1000) }\end{array}$ & $\begin{array}{l}\text { Tasa mortalidad neonatal } \\
\text { (muertes neonatales/ } \\
\text { nacidos vivos*1000) }\end{array}$ & $\begin{array}{l}\text { Tasa mortalidad infantil } \\
\text { (muertes menores de un } \\
\text { año/nacidos vivos) }\end{array}$ \\
\hline 4 '53* & 1 '97* & $2,86 *$ \\
\hline
\end{tabular}

* Por mil nacidos vivos. Fuente: Instituto Nacional de Estadística (2017)

Sin embargo, existe importante controversia en cuanto a la fiabilidad de los datos oficiales, pues hay autores que consideran que en España existe una infradeclaración de los casos (Cassidy, 2013; Cirera, Martínez, Salmerón y Navarro, 2008; Pastor Montero, 2016), debido a cuestiones relativas a la metodología de registro y los criterios de inclusión/exclusión.

Las causas de la pérdida perinatal pueden ser múltiples y complejas, no siendo posible identificar causa de la misma en muchos casos, siendo este un significativo factor de frustración e impotencia en los padres y, por tanto, un obstáculo para la elaboración del duelo (SEGO, 2011).

Es importante tener en cuenta que en las pérdidas perinatales se experimentan las mismas reacciones que en otras situaciones de duelo, y estas pueden tener repercusiones psicopatológicas en personas más vulnerables a quienes no se atiende adecuadamente. Por otra parte, la no elaboración del duelo puede afectar también a embarazos posteriores y en la relación con el siguiente bebé.

\section{Pérdidas Perinatales que inician un proceso de duelo}

Cuando hablamos de duelo perinatal, nos vamos a referir al proceso iniciado tras cualquier pérdida acaecida desde la concepción hasta el primer año de vida (López, 2011; Kowalski, 1987). Se incluyen por tanto:

- Embarazo ectópico

- Aborto espontáneo o inducido

- Reducción selectiva de embriones

- Muerte de un gemelo en gestación

- Feto muerto intraútero o intraparto

- Muerte de prematuro /neonato

- Bebés nacidos con anomalías congénitas

- Bebés dados en adopción (el bebé vive, pero se produce un desprendimiento, que conlleva un duelo)

Existen algunos aspectos comunes, descritos en la literatura y observados también en la práctica clínica, dependiendo de las situaciones anteriores. Así, el aborto que se produce antes de las 12 semanas no siempre 
resulta traumático. Esto en parte es debido a que esta posibilidad está en la mente de muchas mujeres, por lo que es frecuente que no se comunique o difunda el embarazo hasta pasado ese periodo. Sin embargo, no es así para todos los padres y esta pérdida no está reconocida como tal, ni en el ámbito sanitario ni social. Las madres pueden sentirse en falta por no haber podido gestar a ese bebé, con el consiguiente impacto sobre su autoestima. Como consecuencia de esto, se pueden infringir autorreproches y aflorar sentimientos de culpabilidad. Se suelen calmar detallando lo ocurrido, pudiendo compartirlo con su pareja, e interesándose por experiencias similares.

En el caso de una interrupción voluntaria, es bastante frecuente que se oculte la misma o se oculte la voluntariedad, relatándola como un aborto espontáneo. A menudo existe un sentimiento de ambivalencia que es difícil de tolerar. Se puede entender bien como un acto de cuidado hacia ese bebé, que podría haber nacido con malformaciones severas, graves enfermedades e incierto pronóstico vital, o como un asesinato evitable. Los valores morales individuales juegan en este sentido también un peso significativo.

Por otra parte, los avances técnicos en el ámbito de la fertilidad remiten a conquistas, pero también a pérdidas reiteradas. Esas técnicas posibilitan la consecución del deseo de ser padres, incluida la constitución de nuevas estructuras familiares, con madres solas o parejas homosexuales. Junto a esto, enfrenta a muchas mujeres a la primera de las pérdidas, que es la producida por la imposibilidad de poder concebir como el resto de madres, a la que se añaden otras desilusiones cuando en diferentes intentos de fertilización los resultados no son exitosos y en edades que se van alejando de la juventud. Por otra parte, cuando varios embriones han sido fecundados y se plantea la reducción de alguno de ellos, por no existir viabilidad para todos, los padres se ven enfrentados a tomar esta decisión entre las 10-12 semanas y en condiciones de presión de tiempo. Este proceso se suele llevar en soledad por parte de la pareja y aún más en caso de una madre sin pareja. Un tercio de los progenitores recuerdan la intervención con temor, estrés y dolor emocional (López, 2011). No es extraño que se pregunten qué habría sido de esos hijos si hubieran vivido, o de su propia vida y familia con ellos. Junto a lo anterior, hay que considerar que la pérdida en embarazos múltiples es hasta 7-8 veces superior al embarazo único (Chitrit et al., 1999; López, 2011). También las expectativas frente a los embarazos gemelares son especiales en el propio entorno social. Cuando es solo un feto el que se pierde, en la consideración de ese bebé hay que incluir, por tanto, la de ser un gemelo. Si la pérdida de ese gemelo se produce intraútero durante la gestación, la situación es muy delicada para la madre ya que es frecuente que deba continuar la misma con un feto vivo y otro muerto dentro de sí. Es obvio, en estos casos, la necesidad de un gran apoyo. En todos los casos, coexisten la pena por el bebé perdido y la ilusión y alegría por el que ha sobrevivido.

Cuando el fallecimiento es de un neonato, los problemas implicados en su supervivencia pueden haberse detectado antes del parto o presentarse de forma sorpresiva. En ambos casos, se produce un duelo anticipatorio, en el que se enfrenta la pérdida del bebé esperado, vivo, sano y exponente de las expectativas depositadas, y se anticipa la muerte del bebé real, si ha nacido con una incierta posibilidad de sobrevivir. Esta circunstancia conlleva, a nivel psicológico, una comprensible ambivalencia entre el apego a ese bebé enfermo y el desapego por el temor a que no sobreviva. A nivel conductual, esta ambivalencia se puede mostrar como distancia emocional y/o física o constante presencia y estado de alerta por todo lo que sucede a su alrededor. Debido a esto, no es tan infrecuente que algunas madres no se atrevan a coger en brazos o tocar al bebé. Así mismo, es frecuente que las condiciones particulares de salud de los propios neonatos, algunos de ellos grandes prematuros, no permitan tampoco este contacto físico, por el impacto que tiene sobre su regulación biológica, lo que a su vez condiciona el tipo de vínculo.

Cuando se desea el fallecimiento del bebé, aspecto que se oculta a menudo, como forma de acabar con el sufrimiento de todos, puede surgir un gran sentimiento de culpa. También es una dura decisión para los padres, cuando se les plantea la necesidad de reducción de esfuerzo terapéutico, teniendo que participar en el momento para llevarla a cabo.

Aunque podamos situarlo en otra categoría de pérdidas, ya que forma parte de la deliberación y decisión voluntaria, desprenderse de un recién nacido para iniciar un proceso de adopción no está exento de una vivencia psicológica cargada de todo tipo de ambivalencias y conflictos a nivel emocional. Si el inicio del proceso es voluntario, el temor al juicio social sobre esta decisión conlleva, en muchos casos, la ocultación del hecho y la negación de cualquier sentimiento que ponga en contacto con el dolor de la pérdida, intentando vivir como 
si esta no se hubiera producido. Con demasiada frecuencia, esta desconexión entre los aspectos emocionales y los argumentos más racionales no permite sentirse en duelo o pedir ayuda.

\section{El dolor del silencio}

A pesar de la cada vez mayor sensibilización ante la pérdida perinatal, como hemos señalado con anterioridad, en muchos ámbitos se sigue minimizando el impacto de la misma, lo que, pasado un primer tiempo, obliga a vivirlo en soledad.

El inicio del duelo se puede iniciar de forma abrupta con la noticia de la sospecha de la pérdida o, directamente, por la constatación de la misma, siendo en estos casos la ausencia de latido cardíaco la prueba de certeza (SEGO, 2011).

Resulta tan devastadora la comunicación de esta noticia, que algunas mujeres desean una inducción del parto inmediatamente tras el diagnóstico, ya que no pueden soportar la idea de llevar un bebé muerto en su interior, considerando que así cierran el proceso cuanto antes. Otras, por el contrario, desearían contar con un tiempo para hacerse a la idea de la pérdida y facilitar el proceso de duelo, despidiéndose de su bebé sin prisas y de un modo especial (Robert y Silver, 2007; Álvarez et al., 2012; Pastor Montero, 2016).

En otros casos, el riesgo vital inminente del neonato o la severa incertidumbre sobre su viabilidad marca un camino repleto de intervenciones, muchas veces invasivas, cambios bruscos en la evolución y esperas que suponen un gran sufrimiento para los padres. La propuesta de reducción de esfuerzo terapéutico por haber agotado todas las alternativas posibles supone un momento muy traumático y trágico, ya que ningún padre está preparado para semejante noticia.

Ambos supuestos conllevan un inevitable choque emocional. Es habitual que los padres experimenten una compleja mezcla de sentimientos, que puede ser difícil de manejar (tristeza, incredulidad, negación, ira, culpa...), dificultando la capacidad de procesamiento de la información en un momento en el que, además, se verán obligados a tomar ciertas decisiones, algunas de ellas bajo presión de tiempo.

\section{Características específicas del Duelo Perinatal}

El proceso de duelo perinatal presenta una serie de características que lo hacen diferente a otros duelos, representando un duelo múltiple.

Además de la pérdida real del bebé, representa múltiples pérdidas para los padres. Entre estas pérdidas, se incluyen:

- La del hijo proyectado. Supone la "pérdida de una relación más simbólica que real, construida por la imaginación del que está en duelo y basada en sus necesidades y deseos” (Brier, 2008, p. 455).

- La plenitud de la pareja, representada por la espera y llegada de un hijo.

- De una etapa de la vida marcada por el momento de convertirse en padres o la composición familiar imaginada, esperada o idealizada dentro de un proyecto de familia, debido a la ausencia real de un hijo al que no se ha podido conocer, se ha conocido sin vida o ha fallecido precozmente. Se pierde, por tanto, todo un futuro esperado con motivo del nacimiento de ese bebé (Côte-Arsenault y Denney-Koelsch, 2011).

- De algún aspecto de sí mismos con motivo de ese embarazo y de tener ese hijo. A modo de ejemplificación, podemos fijarnos en que, durante el embarazo, la mujer experimenta una unión biológica con el feto, que representa de una manera idealizada, la mejor parte de ella misma (Montesinos, Román, Muñoz y Elías, 2013)

- De un sueño y de una creación (Kowalski, 2001), ya que el bebé representa la vida y es la antítesis del final de la misma y los padres desarrollan sentimientos de esperanza e ilusión proyectados hacia el futuro, sin poder anticipar un desenlace infeliz (Montesinos, Román, Muñoz y Elías, 2013).

- En algunos casos, también puede quedar comprometida la posibilidad de trascendencia. Puede ser que, por sus circunstancias particulares (edad de la madre, técnicas de fertilidad empleadas, secuelas...), los padres 
tengan la sensación de perder su última oportunidad para la maternidad/paternidad, lo cual genera al mismo tiempo un duelo por la infertilidad (López, 2011; Pastor Montero, 2011).

Esta condición de duelo múltiple, en un contexto en el que frecuentemente no se recibe el apoyo y comprensión suficiente por parte del entorno, puede suponer un "trauma acumulativo" (Santos, Yañez y Al-Adib, 2015, p.220), con iguales o mayores consecuencias que la propia pérdida y que conlleva complicaciones significativas en el proceso de recuperación psicológica de los padres.

En otro orden de reflexión, la complejidad del duelo perinatal se puede poner en relación a que, prácticamente, los cinco sistemas motivacionales fundamentales descritos por H. Bleichmar, se articulan y quedan comprometidos en este proceso de duelo: hetero-autoconservación, apego, narcisismo, sensual-sexual y regulación psicobiológica (Bleichmar, 1999). Unos u otros podrán activarse en diferentes momentos y articularse en mayor o menor medida, dependiendo de la historia biográfica y motivaciones internas puestas en juego en la gestación de ese hijo y las expectativas depositadas. Si tras la pérdida que da inicio a un duelo, se alteran las funciones que cumplía para ese sujeto (Bleichmar, 2010a), con la pérdida de ese hijo, además del equilibrio psicológico personal, se modifica la interrelación de la pareja y de la familia en su conjunto.

A modo de ejemplo y de forma simplificada, si el bebé satisfacía para la madre necesidades relativas a sentirse segura, en la relación con su pareja por ejemplo, la consecuencia de su pérdida puede ser la aparición de un sentimiento de inestabilidad o peligro, que se puede extender también al temor por la salud de los otros hijos, si los tiene, o de la suya propia; si aportaba un sentimiento de vitalidad, su pérdida puede provocar apatía; si lo que está mayormente en juego es el narcisismo, su desaparición genera desequilibrio, pérdida de autoestima y valor; si satisface prioritariamente su necesidad de cuidar, proteger y ofrecer felicidad, su pérdida puede activar sentimientos de culpa, sensación de vacío y confusión, ya que esa pérdida arrasa con una parte de la identidad relacionada con ese cuidado del otro .

No podemos olvidar tampoco que el embarazo es una época de desestabilización psíquica. Se producen cambios en el cuerpo, en las relaciones íntimas, en las relaciones familiares y sociales y en la propia identidad de la mujer que, integrados en la biografía de forma adecuada, dan lugar a una organización psíquica más compleja (Kofman e Imber, 2005).

Para muchas mujeres, la gestación representa un momento de gran plenitud y realización personal. Sin embargo, también existen otras situaciones que pueden llevarlas a vivir su embarazo con ambivalencia o ansiedad, poniendo en cuestión el propio deseo de tener un hijo (Dio Bleichmar, 2009). La inmadurez psicológica, relación de pareja, situación económica o entorno violento, entre otras, pueden constituir una experiencia alejada del ideal imaginado a nivel general (Garriga, 2009).

Puede ocurrir también que la mujer atraviese por una depresión durante su embarazo, lo que aumentaría el riesgo de psicopatología posterior y duelo patológico. Si esta no es muy grave, puede no ser identificada, confundiéndose con quejas comunes relativas a cansancio, falta de energía, dolores vagos o insomnio. En los casos más graves, con aparición de sintomatología francamente depresiva, es más común que sea diagnosticada. Sin embargo, en ambos casos, es frecuente que la futura madre se cuide peor a nivel de salud general, alimentación y sueño, posibilidad de consumo de alcohol, tabaco u otros tóxicos y, sobre todo, con menor búsqueda de ayuda (Lartigue, Maldonado-Durán, González-Pacheco y Sauceda-García, 2008).

Para la atención clínica al duelo, será necesario tener en cuenta los aspectos anteriores, tanto a nivel preventivo como para el tratamiento del duelo patológico.

\section{Actitudes frente a la pérdida perinatal}

Como venimos comentando, las actitudes pueden ser muy variadas, dependiendo de variables personales de los padres y de la cultura propia, estando en constante interacción. La comprensión de dichas actitudes frente al duelo pasa por conocer el lugar atribuido a ese hijo en el mundo afectivo de los padres. Dicho lugar emocional, que no tiene que ver solo con la edad gestacional, va a jugar un peso importante en la posición que adopten frente a su pérdida. Este aspecto vincular implicado en el duelo es escasamente reconocido en nuestro contexto, por lo que, habitualmente, también el acompañamiento prestado es escaso. La idea de que cuanto 
más temprana sea la pérdida, menor será la intensidad y duración del duelo (Lovell, 2001; López, 2011), cuenta con especial arraigo, esperando una superación rápida del mismo. A pesar de los avances históricos y de la mayor sensibilidad actual, la pérdida perinatal sigue velada por una especie de tabú, que de algún modo intenta hacerla invisible, lo cual deja a los padres sin el apoyo social y el reconocimiento legal necesario.

La minimización del duelo va pareja a la falta de soporte emocional a los padres, con las consecuencias que puede acarrear. Precisamente un aspecto particularmente complejo del duelo perinatal, junto a los mencionados anteriormente, es que no recibe ni el apoyo de la red social, ni el pertinente permiso para ser sentido y expresado, pudiendo considerarse un "duelo desautorizado" (Doka, 2002). Si no se reconoce el vínculo con el feto o bebé, tampoco la pérdida puede ser reconocida. Por la misma razón, si no se reconoce como muerte la pérdida fetal, tampoco el derecho al duelo de los progenitores (López, 2011). La desautorización, la falta de empatía, de comprensión y apoyo en torno a la pérdida perinatal es, en sí misma, otra pérdida secundaria (Payás, 2010).

No podemos olvidar que, para favorecer respuestas adaptativas y que los padres puedan tolerar los sentimientos desagradables derivados de la pérdida, es fundamental que no se sientan solos y contar con un apoyo emocional suficiente. La urgencia por imponerles una rápida recuperación, debido a esta falta de reconocimiento, supone un estrés añadido y un obstáculo para el mismo proceso de adaptación (Álvarez, Claramunt, Carrascosa y Silvente, 2012; Pastor Montero, 2016).

Este tipo de duelos no permitidos, con escasos ritos de despedida y sin lugar en la mayoría de las religiones, representan un importante riesgo de no elaborarse adecuadamente. Generan sentimientos de vergüenza, culpa e inadecuación cuando no se superan rápidamente.

La vivencia de la pérdida y el curso del proceso de duelo también suelen ser diferentes en el padre y en la madre, lo que puede dar lugar a desencuentros, incomprensiones y sentimientos de extrañeza y soledad frente a la pareja, no siendo tan infrecuente que se produzcan alteraciones en la relación. Sin embargo, en otros casos, el vínculo de la pareja se hace más fuerte, tras el afrontamiento y la elaboración conjunta de la experiencia.

El padre suele mostrar menor afectación que la madre, ya que en ella el apego empieza desde que constata su embarazo, imagina la maternidad y aumenta considerablemente con la percepción de los movimientos fetales, jugando un lugar relevante los aspectos físicos y biológicos de llevar ese hijo dentro de sí. En el caso del padre, el apego se produce a un nivel más cognitivo, acercándose a los aspectos físicos a través del cuerpo de la madre y, actualmente, a través de la visibilidad que aportan las actuales técnicas de imagen sobre el cuerpo del bebé. Estas diferencias en el apego generan también diferentes expresiones y ritmos en el proceso de duelo.

Algunas de las mayores preocupaciones de los padres en el duelo se encuentran no tanto depositadas en la pérdida del bebé, sino en cómo consolar a la madre y sobre la posibilidad de descendencia, si podrán tener más hijos.

Suele ser también el padre quien asume la responsabilidad de informar a la familia y amigos y las cuestiones burocráticas y gestiones sobre el destino del cuerpo, como por ejemplo el entierro.

Las expectativas sociales frente a la reacción del padre también son diferentes que las que se depositan sobre la madre. Si de ella se puede aceptar en los momentos iniciales un desmoronamiento, en el caso del padre se espera que él apoye física y emocionalmente a la madre. Es muy frecuente que la pena por su mujer se imponga a su propio duelo, condicionando así su propia vivencia de la pérdida, apareciendo cierto alejamiento para poner toda su atención y cuidado en la madre. Debido a esto, es fácil que evite confrontaciones que puedan poner en evidencia sus emociones y que transforme su malestar en enfado contra el personal sanitario, atribuyéndole la responsabilidad del desenlace y sin aceptar lo inevitable del mismo.

La reacción de los hermanos va a depender también de diferentes variables, como la edad, el sexo, personalidad, lugar de la fratria y también de la cultura y/o religión de la familia. Sin ninguna duda, captarán la tristeza y disgusto de sus padres, lo que también producirá en ellos un pesar o temor, con manifestaciones acordes a su etapa evolutiva. Llevados por el egocentrismo infantil, pueden sentirse culpabilizados por creerse causantes de la pérdida, si han sentido envidia o se han podido sentir desplazados. En cualquier caso, los padres tendrán que afrontar también en relación a ellos la tarea de informarles al nivel que puedan entender, intentando tranquilizarles y haciéndoles partícipes en la medida que puedan de los rituales de despedida. Es importante, por tanto, integrarles en el proceso. 


\section{Aspectos clínicos específicos del duelo perinatal.}

Las manifestaciones clínicas del duelo perinatal, como reacción o trastorno adaptativo, involucran aspectos biológicos y físicos, emocionales, cognitivos y conductuales, que pueden ser intensos y difíciles de manejar durante el periodo de duelo, pero que pueden ser considerados normales y coherentes con la situación que se está viviendo. Si bien es frecuente la sintomatología ansioso-depresiva, esta puede alcanzar características clínicas en algunos casos, fundamentalmente si se presentan en conjunción la frecuencia e intensidad de los síntomas y su duración mantenida durante un periodo de tiempo suficiente como para pensar en la presencia de un duelo crónico o patológico. Así, en el funcionamiento de la persona en duelo y deprimida quedan involucrados, no sólo aspectos relacionados con la pérdida, sino una amplia de gama de proyectos personales e interacciones. Será necesario discriminar correctamente estas situaciones, con el fin de poder ofertar la atención adecuada a las madres o parejas que puedan precisarlo. Como sintomatología más frecuente, encontramos (Moscarello, 1989):

- A nivel físico: estómago vacío, opresión, dificultad respiratoria, debilidad, fatiga.

- A nivel emocional: shock, vacío, rabia, fracaso, autorreproche, culpa, incredulidad, confusión, despersonalización.

- A nivel cognitivo: reexperimentación con ideas intrusivas, dificultades de concentración y toma de decisiones. Fenómenos perceptivos como oír el llanto o sentir sus movimientos.

- A nivel conductual: insomnio, pesadillas, falta de apetito, aislamiento social, evitación de mujeres embarazadas y niños.

Algunas diferencias cualitativas también nos pueden ayudar a diferenciar el duelo de la depresión. Es muy frecuente que las mujeres en duelo muestren tristeza por el hijo perdido, mostrando empatía hacia el mismo, con preocupaciones relativas a si habrá sentido dolor y su bienestar en el proceso. Es frecuente que aumente su sentimiento de pena cuando ven a otros bebés y evitan también el contacto con embarazadas. Suelen llorar y buscar apoyo, necesitando hablar y compartir lo ocurrido. Si presentan autorreproches, suelen estar limitados a no haber hecho lo suficiente por el feto/bebé o no haber estado a la altura y no presentan ideación autolítica (Beutel, Will, Völkl, Von Rad y Weiner, 1995).

En el caso de la depresión, priman los recuerdos desagradables del embarazo, a la vez que se produce una idealización del feto/bebé fallecido. Se produce un abandono de las relaciones, por lo que se aíslan, rechazando la posibilidad de ayuda y sustituyendo esta por la autocompasión, a la vez que se muestran muy irritables con su entorno. El sentimiento de culpabilidad y desvalorización abarca la globalidad y pueden ser relativamente frecuentes las ideas de suicidio (Beutel et al., 1995).

Además de la depresión, podemos delimitar otros factores de riesgo a tener en cuenta, que aumentarán la vulnerabilidad personal, como la presencia de antecedentes psiquiátricos previos; las pérdidas recurrentes y la ausencia de otros hijos, de pareja estable o familia y apoyo social; la falta de explicación sobre lo ocurrido; y la coincidencia con otros acontecimientos vitales estresantes (Neugebauer et al., 1992; Athey y Spielvogel, 2000).

\section{Programa de Enlace para la atención al duelo perinatal}

La sensibilización de los profesionales hacia las necesidades emocionales que presentan las madres en situación de duelo perinatal y el compromiso y apoyo de las Jefaturas de Servicio de Neonatología, Obstetricia-Ginecología y Psiquiatría y Salud Mental en dar respuesta a las mismas, ha favorecido en el Hospital Universitario 12 de Octubre de Madrid el desarrollo de un Programa de Enlace para la Atención Psicológica al Duelo Perinatal, en el que se encuentran implicados los servicios mencionados.

Este programa, no cerrado aún en su desarrollo e implementación, implica un trabajo codo a codo entre todos los profesionales que participan en el mismo, en el que se comparten criterios de actuación frente a las situaciones complejas y cotidianas que se plantean con las pacientes. La colaboración se extiende también, y en la medida de lo posible, a intentar responder a determinadas necesidades formativas, detectadas desde 
los servicios mencionados, ya que acompañar y cuidar a los padres en el duelo no es algo que pueda improvisarse, sino que requiere de habilidades de comunicación y de técnicas y estrategias de ayuda.

A grandes rasgos, este programa se centra en tres elementos principales: el ofrecimiento de atención psicológica inmediata en pérdidas detectadas o acontecidas en el periparto; el seguimiento emocional de los padres cuyos bebés se encuentran ingresados en la UCI de Neonatología en situación de riesgo vital; y, en ambos casos, el seguimiento psicológico posterior en consultas hospitalarias ambulatorias tras el fallecimiento. Dicho seguimiento posterior puede ser realizado a nivel individual y/o grupal, como en el caso que vamos a desarrollar posteriormente.

Se contempla también la atención y seguimiento psicológico en embarazos posteriores, en los que se activan fuertes ansiedades relativas al bienestar y viabilidad del bebé. Con mucha frecuencia y debido a esto, se observa una marcada falta de regulación, tanto a nivel físico como cognitivo y emocional. Junto a lo anterior, a veces se generan mecanismos de autocontrol compensatorios, que pueden evolucionar hacia cuadros clínicos, si no se interviene precozmente.

Se colabora también en el Servicio de Medicina Fetal, de forma más puntual, cuando se detectan casos con anomalías congénitas, malformaciones o enfermedades, a veces en momentos avanzados de la gestación, precisando las madres un espacio para compartir el impacto emocional que se deriva de esta noticia y el esclarecimiento para la toma de decisiones. Junto a lo anterior, también se presta atención en casos específicos en los que se plantea la posibilidad de adopción, tanto a iniciativa de la madre, los padres o los profesionales, en casos especialmente complejos.

La realización de este trabajo dentro de un marco institucional público y sujeto por tanto, a dinámicas institucionales (jerarquías, normativas, objetivos, posibilidades, funcionamiento intraequipos e interequipos...) precisa también un conocimiento y comprensión de dichas dinámicas institucionales, con el fin de favorecer que las intervenciones vayan claramente dirigidas al mayor beneficio del paciente y que no queden obstaculizadas o ralentizadas por fenómenos primitivos derivados de las mismas (Utrilla, 1998). En este sentido, no podemos perder de vista que la actitud de los profesionales, en momentos de tan alta vulnerabilidad para las madres y padres, repercute en el proceso de duelo, tanto en sentido positivo como negativo, con mucha mayor huella de la que a priori se le supone. Sin embargo, tenemos que considerar que dichas actitudes también están condicionadas por el propio impacto que estas situaciones provocan en los profesionales (Steen, 2005; Pastor Montero, 2007, 2011).

Así como esta experiencia no es ajena en el día a día de los hospitales, las emociones intervinientes tampoco lo son para los profesionales. Son muy comunes los sentimientos de pena, rabia, ansiedad, inseguridad, sensación de fracaso e impotencia que se vivencian por no haber podido sacar un bebé adelante o por tener que comunicar tan triste noticia a unos padres ilusionados y ajenos a lo que iba a ocurrirles. En este contexto, algunos profesionales se distancian emocionalmente para proteger su propia vulnerabilidad y otros, por el contrario, se identifican masivamente con esos padres en duelo, sin poder conseguir una distancia adecuada que permita su contención emocional. De esto se deriva la gran importancia de la formación en estrategias de comunicación, en competencias relacionales y, por supuesto, la coherencia y el trabajo en equipo de los profesionales implicados.

Esta formación específica, además de disminuir su propio malestar subjetivo, evita que el cuidado se refiera sólo a aspectos físicos, y que contemple también los emocionales.

Si bien comunicar la grave noticia genera ansiedad en los profesionales, poder contar con un espacio de intimidad, comunicarla a los dos padres a la vez, asegurarse de que están entendiendo lo que escuchan y ofrecer un lugar adecuado para despedirse, puede servir de ayuda tanto a padres como a profesionales. Para los profesionales, prestar esta ayuda desde la empatía con los padres, supone una variable muy relevante en el manejo de sus propias emociones. Es importante considerar que la sobresedación en el parto debería ser evitada y que es importante sugerir la posibilidad de ver, tocar o coger al bebé, así como guardar algún recuerdo, pero siempre respetando la decisión de los padres, como elementos de realidad que favorecen el trabajo de duelo. 


\section{Grupo de padres duelo perinatal}

\section{Conceptualización}

Partimos de un marco teórico que nos hace considerar el duelo perinatal como un proceso no patológico, pero que conlleva intenso sufrimiento para los padres y que representa una clara crisis vital y familiar. El desbordamiento emocional, angustia y sintomatología de tipo depresivo y/o ansioso pueden ser muy intensos, requiriendo un importante apoyo emocional, así como comprensión y empatía para que puedan ser contenidos. Se considera la vivencia compartida como un elemento que potencia las posibilidades de elaboración del duelo, y que da un lugar colectivo a la pérdida, ofreciendo la posibilidad de percibir realidades similares y de reconocer sentimientos también similares a los propios, sin sentirse juzgados por ellos. Aumenta, a la vez, la posibilidad de empatía con el otro, extendiéndose esta a otros personajes que se encuentran fuera de nuestras sesiones. Esta intervención, realizada en un marco grupal, aumenta, por tanto, las posibilidades de identificación, modula la emocionalidad y favorece la integración de esta experiencia en la biografía personal de la madre y de la relación de pareja. Difiere de un grupo de autoayuda, en el sentido de que se trabaja con variables psíquicas y antecedentes personales compartidos en las diferentes sesiones, siempre circunscritas al proceso de duelo de forma focalizada. Por otra parte, el rol del conductor-terapeuta del grupo es asimétrico en relación a los demás miembros, aportando su comprensión del psiquismo implicado en el duelo.

\section{El grupo}

- La realización del grupo es una de las actividades, no la única, que se lleva a cabo para la atención psicológica en las situaciones de duelo perinatal.

- Los aspectos biográficos se han modificado para que los participantes no puedan ser reconocidos, si bien puede haber similitudes con la situación de diferentes personas con experiencias similares.

- Los datos que aportan los padres en su descripción de lo ocurrido no reflejan la situación médica real, sino lo que ellos transmiten de la misma y sus vivencias más significativas.

- Los contenidos trabajados a lo largo del grupo se derivan de las características específicas de estos participantes en concreto, si bien hay bastantes aspectos que se observan en otros grupos de perfil similar.

- La conducción del grupo se lleva a cabo por una psicóloga clínica y participa, en calidad de observadora, una residente PIR, con la que se analiza posteriormente cada sesión y se elaboran las situaciones planteadas, de forma que nuestra reflexión pueda ser utilizada para avance de grupo. Puntualmente acude algún estudiante psicólogo en prácticas.

- Se realizaron ocho sesiones, con carácter quincenal y de hora y media de duración, que se prolongaron durante cinco meses, teniendo en cuenta alguna interrupción por fiestas.

- En principio, se ofrece la participación en el grupo a pacientes sin antecedentes previos en el ámbito especializado de salud mental.

- Acudieron doce participantes en total, de los cuales, cinco eran parejas de padres y dos madres solas, de las cuales una no tenía pareja. Otra pareja que había sido derivada no acudió.

- En la mayoría de ellas, se había activado la petición de atención psicológica durante su ingreso en el hospital, con motivo de la pérdida perinatal o mientras sus bebés se encontraban en la UCI de Neonatología, según protocolo acordado en el Programa de Enlace descrito.

- Excepto una madre, el resto había mantenido consultas individuales o con su pareja a nivel ambulatorio en el ámbito del hospital, hasta la realización del grupo.

- Una madre fue derivada al centro de salud mental de su zona para continuar tratamiento del duelo, por detectar especial fragilidad y rasgos de personalidad que así lo aconsejaban.

- El tiempo transcurrido desde la pérdida fue variable, situándose en todos los casos antes de los diez meses desde la pérdida. 


\section{Objetivos}

- Compartir las diferentes experiencias en un marco de contención que permita el proceso adecuado de elaboración del duelo.

- Promover el avance en el proceso a través de los diferentes momentos en que se encuentran los participantes.

- Detectar y canalizar las situaciones de riesgo de duelo patológico.

\section{Intervenciones}

- Legitimar los sentimientos derivados del proceso de duelo.

- Favorecer la expresión de diferentes perspectivas por parte de la pareja, para una elaboración conjunta que permita la comprensión mutua.

- Utilizar la identificación entre unos y otros miembros del grupo para facilitar la integración de la experiencia traumática.

- Compartir experiencias gratificantes derivadas del embarazo, que permitan el recuerdo e incorporación de aspectos positivos.

- Comentar estrategias de manejo en el ámbito familiar y social.

- Ofrecer narrativas alternativas que ayuden en el proceso de duelo.

- Acompañar en las dudas, temores, incertidumbres.

- Vincular pérdidas y traumas del pasado con el duelo presente, siempre con el énfasis del trabajo con el aquí y el ahora.

- Mejorar las estrategias de afrontamiento, incrementando la reincorporación sociolaboral y los mecanismos de autorregulación emocional y de regulación relacional.

Primera sesión. Presentación de los participantes y encuadre del grupo:

- A Y B: Perdieron su bebé a los seis meses de gestación. A los cinco meses y medio se detectó taquicardia en el feto. Tuvo que dar a luz. La situación fue muy difícil. Tuvo que contarlo a su hija de seis años. Estuvo quince horas de parto, sabiendo que su hijo iba a nacer muerto. Entre ellos habían hablado que si el bebé venía mal, interrumpirían el embarazo. Ella siente que si hubiera aguantado más, igual hubiera vivido. Se siente culpable por ello.

- C: Portadora de una enfermedad genética. Fecundación in vitro (FIV). Embarazo gemelar. A los seis meses, borramiento del cuello. Parto por cesárea de urgencia. Los bebés nacieron. La niña vivió dos días y el niño cuatro. La niña tenía un derrame cerebral que le produjo lesiones incompatibles con la vida. El niño también tenía muchas secuelas. Tuvieron que tomar la decisión de "desenchufarlos" por daños incompatibles. Le costó mucho bajar a verlos a la incubadora. Se sentía mala, egoísta, como si no quisiera hacerse cargo de ellos. También los cogió hasta que fallecieron. Era la primera vez que podía cogerlos, tocarlos.

- G y F: Desde la primera ecografía, les dijeron que había algún problema que había que observar. En la siguiente les hablaron de malformación cerebral. Finalmente tuvieron que interrumpir el embarazo a los siete meses, tras consulta al Comité de Ética. Han tenido otros tres abortos anteriores y tienen otro hijo de cinco años por FIV. A él le dijeron que pedirían otro bebé a la cigüeña. Le explicaron también que, antes de él, había otros bebés que no nacieron y también después de él. Este había sido un embarazo natural. Entre ellos han estado enfrentados, ya que él no quiso verlo. Ella es creyente y antiaborto. Hubiera tirado adelante con una niña con una minusvalía, pero tuvo que decidir por su marido e hijo. Ella trabaja en un centro de discapacitados y no sabe si va a atrever a volver al trabajo. Siente vergüenza. Le parece muy fuerte animar a otros padres con sus hijos, y ella haber tomado esta decisión. Gracias a verla, lo pudo aceptar.

- A y N: En la semana veinte, no encontraban una arteria. En la segunda ecografía, ya no había latido. Tuvieron que "expulsarle". Hace mes y medio que tenía que haber nacido. No lo vieron, ya que les dijeron que podía tener malformaciones, aunque luego no las tuvo... Nunca lo notó dentro de sí. Se culpaba ella, por no tener explicación a porqué había ocurrido eso. Después se sintió mala madre por no haberlo queri- 
do ver. Ahora está muy agobiada porque le dicen que puede volver a intentarlo. También tuvo muy mala experiencia con su médico de cabecera, que quería que se incorporara inmediatamente al trabajo. Estuvo al final un mes de baja.

- G: En la semana treinta y tres diagnosticaron un derrame cerebral, sin saber el alcance del mismo. A los dos días de esta noticia ya no había latido. Le hicieron una cesárea y pudo tenerlo en brazos una hora. Sentía miedo, pero al final lo vio. Su hijo pesó 2.400 gramos. No pudo hacerle ninguna foto. No se sabe la razón y eso le angustia mucho. Fue sola a la ecografía, ya que su marido estaba trabajando. Dice que ella hubiera preferido que viviera, aunque hubiera nacido mal. Luego piensa en su hija de seis años y se conforma algo más. Dentro de un mes, tendría que haber nacido su hijo. Su marido está trabajando y no puede venir al grupo. Tiene envidia de otros que sí tienen a sus hijos recién nacidos. Dice que de momento no quiere tener más hijos. Ante la falta de explicación, se llegaba a preguntar si se habría drogado o si se habría dado algún golpe o habría comido algo, para que ocurriera eso.

- M y L: Primer hijo. En la semana veinte vieron que tenía el fémur reducido para su edad y presentaba un crecimiento retrasado, como si fuera de la semana diecisiete. Les dijeron que moriría dentro, pero aguantó. Se vio que su placenta era pequeña y que no se alimentaba. Cada semana les decían que no sabían si tendría latido a la siguiente. En la veintisiete, le provocaron el parto. Nació con 450 gramos y vivió una semana. Nació por cesárea, por eso ya no podrá tener un parto natural. También se sintió culpable porque su placenta no funcionó correctamente

- R y C: Consiguieron mediante FIV embarazo de mellizos. Durante cinco meses el embarazo fue ejemplar. Empezó a tener molestias, acudió al hospital y era un borramiento del cuello del útero. Le colocaron un pesario y estuvo de reposo cuatro o cinco días en el hospital. Le dieron el alta con la idea de reposo total. Al salir del hospital, se encontró peor, volvió y ya les dijeron que no había posibilidades. Fue muy duro. Uno nació muerto y el otro murió al poco tiempo. Ella no pudo verlos, por lo mal que se encontraba, y echa mucho de menos el no haberse podido despedir. Recuerda mucha confusión cuando les dijeron que podían verlos y cogerlos. Entró en pánico desde el momento en que dijeron que tenía que parir. Quería que la sedaran, drogaran... lo que fuera para no enterarse de nada... Fue espantoso notar que nacen y mueren.

\section{Se habla de:}

- Poderse escuchar

- Poder recordar

- Sentimientos ligados al recuerdo

- Situaciones parecidas-personas con quienes nos identificamos

- Decisiones difíciles

- Circunstancias diferentes que llevan a tomar decisiones también diferentes

Segunda sesión. Se recuerdan los nombres de las personas asistentes, se hace un breve resumen de lo hablado el día anterior, recordando algunas de las circunstancias de cada uno. Se comenta cómo se fueron el día anterior.

- A: Sintió dolor.

- G: Le vino bien el grupo. Dice que, a efectos legales, es como si su hijo no hubiera nacido. Dice que la gente no es consciente de que ha nacido. Aquí ha podido hablar de él y expresar su tristeza.

- M: También le dicen que era muy pequeño y que ya tendrá otro. Le ha gustado poder compartir. Fuera todos te dicen que seas positivo y ya...

- C: Para la gente es como si hubieras tenido un aborto, pero era nuestro hijo. Tenía ya su nombre. La gente no sabe cómo estás y te dicen cosas para animar, pero así es todo lo contrario.

Se habla de proceso de la paternidad: desde mucho antes del parto.

- N: Dice que su marido es más fuerte, pero que ella llora mucho. Está molesta porque la gente lo minusvalora. Le dicen que tiene otra hija, pero que no lo sustituye, y ella no quiere hablar con nadie. 
- R y B: Al principio comunicaron el embarazo en redes sociales a todos sus conocidos, ahora él se ha encargado de comunicar la noticia porque ella no se ve con fuerzas. Están muy tristes. Sólo hablan con la gente más íntima.

- C: Apagó el teléfono y no quería hablar con nadie.

- L: Mucho agobio por ver a la gente. Aún no ha conseguido ver a parte de la familia. Le pesa mucho haber tomado la decisión de interrumpir el embarazo, aunque lo haya hecho por su bien, por su calidad de vida. Tiene sentimiento de culpa. Hubiera preferido que su corazón se hubiera parado.

- M: También tuvieron que decidir. El bebé pesaba 450 grs. Dice que si hubiera salido adelante, igual hubiera tenido que estar atado a un máquina toda su vida, lo que durase y que cree que se hubieran sentido aún peor.

- A: Sus niños también nacieron, los dos con derrames cerebrales. La lesión de la niña era incompatible con la vida. El niño tenía comprometida la vista, el oído, el cerebro. Dice, ¿cómo hubiera vivido...? Tiene un vecino con retraso mental y no quería eso para su hijo.

- M: También siente culpa porque no sabe si hizo bien quedándose embarazada. Había tenido otros abortos anteriores y sabía que podía ser difícil.

- G: Trabaja en un centro con personas discapacitadas y no se quita la culpa. Dice que no puede contar a nadie que ha sido una interrupción voluntaria, todos creen que ha sido espontáneo. Ella es antiaborto, había tenido también varios abortos espontáneos y en algún momento pensó en adopción. Para ella todo esto es una losa. También ha supuesto un momento muy difícil para la pareja, ya que su marido sí tenía clara la interrupción y ella lo ha hecho por él.

- C: Tiene un hijo de tres años que presumía de la tripa de ella. Cuando la ve llorar, ella le dice que está triste porque echa de menos al hermanito y que también está contenta por tenerlo a él. Ella está donando la leche y a veces se queda con ella mientras se la saca. Le dice que es para otros bebés que están malitos o que su mamá no tiene leche. Le cuesta separarse de ella. También está sufriendo.

\section{Se habla del sentimiento de culpa:}

- Hablamos de que también se puede tener sentimiento de culpa si se toma la decisión contraria. Hablamos de la calidad y esperanza de vida. Se comenta que las decisiones se toman con la información que se tiene en un determinado momento, y que también influye cómo nos podemos sentir y cómo nos vemos para afrontar la situación. Comentamos que uno intenta decidir lo que nos parece mejor y que eso no es fácil.

- Puede ocurrir que a veces tomemos decisiones que casi son contrarias a nuestras creencias, o a lo que pensábamos que haríamos fuera de esta realidad concreta que nos pasa a nosotros. También es más difícil si la pareja no está de acuerdo o tienen más dificultades para comunicarse. Se comenta también que cuando los profesionales plantean una reducción de esfuerzo terapéutico es porque verdaderamente ven que el bebé se encuentra en una situación extrema, y que no hay viabilidad, por lo que no pueden considerarlo como una decisión unilateral de ellos mismos.

Se habla de la dificultad para manejar y aceptar la incertidumbre, y de la necesidad de elaboración de la realidad, no de lo que pudiera haber sido si se hubieran dado otras circunstancias o de si se hubieran tomado otras decisiones.

Se habla de respetar diferentes ideologías (religiones, creencias...). Todas las opiniones tienen cabida en el grupo, aunque pensemos diferente y vamos a intentar comprender a esa persona, poniéndonos en su piel.

Se habla también del dolor emocional que supone la pérdida para toda la familia.

Tercera sesión. Se tiene después de Navidades. Casi todos hablan de lo tristes que han sido. Algunos se ha quedado en su casa y otros han estado con la familia. Han intentado arroparles, pero aún así lo han pasado mal. Habían imaginado las fiestas de otra manera, sobre todo los Reyes. 


\section{Algunos padres comentan:}

- Lo peor es verla a ella. Nosotros tenemos que intentar ser la parte fuerte. También él ha estado sin ganas en las fiestas, pero lo llevaba mejor que ella.

- Lo peor es ver a tu mujer de bajón. También lo pasó muy mal porque su hija, en el árbol de los deseos, pidió otro hermano y él sentía que no sabía si se lo podrían dar.

- Otro dice que se nota tranquilo y que tiene menos sentimiento de dolor. Esto te enseña otras cosas de la vida. Ahora lo lleva de otra forma. Tiene claro que hay que seguir y que esto es otra experiencia.

- Lo más importante para él es apoyar a su mujer y él, aunque aún está triste, como trabaja, también tiene otras cosas en la cabeza.

- R: Le cuesta mucho ver embarazadas. Le da rabia verlas y más sin son carritos gemelares.

- A: Le resulta muy difícil también ver que nacen otros niños y ver embarazadas. Habla de una amiga que ya tiene dos hijos, se quedó embarazada de un tercero y le sentó tan mal que incluso pensó en abortar... Y ellos, que lo deseaban tanto, lo han perdido.

- D: Cuando ve otras embarazadas, le entran ganas de advertirlas que no estén tan contentas, que puede pasarles algo, como a ella.

Hablamos del sentimiento de envidia que podemos sentir, que puede hacer que nos sintamos mal, cuando vemos que otros padres tienen algo que nosotros hemos perdido.

- Otra pareja cuenta que están yendo a un grupo de autoayuda de una asociación y que una madre dijo que si se volvía loca, qué mejor motivo que la pérdida de un hijo, pero que ella no quiere volverse loca.

- C: Dice que tiene claro que quiere seguir adelante, que no se quiere coger una depresión, ni volverse loca. Dice que ha estado algunos días de bajón, pero que va bastante bien y que se extraña, como si tuviera que estar mal.

Hablamos de que a veces uno se puede sentir culpable por empezar a sentirse bien. Comentamos la necesidad de concederse el derecho a estar contento.

Comentamos que a veces las críticas pueden venir de nosotros mismos y que podemos sentirnos desleales si estamos más felices.

- C: Dice que al principio pensaba que ese sentimiento lo iba a tener siempre presente. Ahora, aunque tenga su pena, le apetece salir y tener proyectos nuevos. Tienen un sonajero y unos patucos en la habitación, los miran y se acuerdan, pero con menos pena.

También hablamos de la diferencia entre estar tristes y estar deprimidos y que superar este duelo consume muchos recursos psíquicos. Podemos quedarnos instalados en el duelo o intentar que sea una experiencia más en nuestra vida, aunque haya sido muy dolorosa.

Se habla también del equilibrio entre no exigirse nada o exigirse en exceso. Poder sentir nuestra experiencia, pero intentando no quedarnos instalados en la pena.

- D: Está intentando relativizar más y eso le hace poder disfrutar de otras cosas.

- G: Tenía mucha necesidad de venir hoy. Aquí se siente muy entendida. Ya tiene un resultado de la autopsia. Le han dicho que tiene incompatibilidad con su pareja a nivel de plaquetas y que podría ocurrir lo mismo en otro embarazo. Aún no ha asimilado la información y no sabe si intentaría un nuevo embarazo. Tiene mucho miedo.

- Otra mamá habla de que quizá no puedan tener más hijos y tendrían que buscar un óvulo donado. Otra dice que en su caso, se podría repetir el crecimiento intraútero retardado (CIR), y el embarazo no seguir adelante, por lo que tampoco podría ser madre. Varias hablan en este sentido.

Hablamos de otro duelo: el de la duda sobre una futura maternidad/paternidad. Comentan sobre el estado de las autopsias, estudios que se están realizando, riesgos que asumirían o no, etc. Se habla de ir paso a paso. 
Hablamos del miedo y de la sensación de riesgo. Uno siente que como te ha pasado una vez, te puede volver a pasar. Es difícil aceptar la pérdida de control sobre la evolución de nuestro embarazo/parto, en cambio, sí podemos hacer algo con nuestras propias reacciones, con cómo lo vamos afrontando.

- B: Ellos decidieron no ver al bebé, pero ahora siente mucha necesidad de haberse despedido. No quiso tampoco ver la última ecografía. Tiene la sensación de no haberse despedido y haberlo abandonado, desplazado.

- D: La matrona la ayudó a verlo. Era una mujer especial. Pidieron que fuera esa matrona quien se lo llevara. Tomaron la decisión de enterrarlo. Ha ido sola al cementerio y ha llevado pegatinas de mariposas.

Hablamos de la posibilidad de despedirnos internamente.

- D: Comenta que antes no quería deshacerse de la ropa y que tenía todo tal cual.

- Varios dicen que aún conservan en casa las cenizas y que no pueden desprenderse de ellas.

Hablamos de poder diferenciar las cosas físicas (cenizas, ropa, muebles, fotos...) del propio bebé que se ha ido. Esas cosas representan al bebé, pero no son el bebé. Comentamos que el bebé siempre va a poder permanecer en nuestro recuerdo.

\section{Cuarta sesión:}

- G: Fue al cumpleaños y se encontró a una amiga a punto de salir de cuentas. Para ella fue impactante. Sabe que esa persona no ha hecho nada, pero le entraron ganas de escupirla.

- A: Fue a otra reunión familiar y su cuñada dio el pecho a su bebé. Comenta que le resultó muy duro y le entraron ganas de irse.

- R: Ayer fue su cumpleaños. Aunque al principio pensó que no tenía nada que celebrar, luego pensó que sí, que entre ellos se quieren y que tiene, que tenían, que celebrar la vida, pero por la noche fue a un concierto y se encontró con una mujer con una tripa gigante y le estropeó todo el concierto. A pesar de eso, hoy se ha levantado con ganas, con mucha paz. Dice que se da cuenta de que tiene momentos malos, pero que son momentos. Su pareja cuenta que pasar por una experiencia así, hace que se fortalezcan vínculos. Les han dicho que en cuatro o cinco meses podrán volver a intentarlo. Te das cuenta de que hay gente que te quiere más.

- D: A principios de semana tuvo un bajón. Quedó con amigos, se lo pasó muy bien y sentía que no se lo podía permitir. Después se acordó de lo que hablamos y pensar que puede disfrutar de las cosas le dio más paz.

- C: El ginecólogo les ha dado ya luz verde para volver a intentar otro embarazo. Comenta que una vecina ha tenido un comentario muy inoportuno con ella, pero que ella no se ha hundido como en otros momentos. Su marido añade que esta vez, en vez de sentir pena por el comentario, lo que ha sentido es enfado con esa vecina. Dice que él ve a su mujer más fuerte.

- El marido de otra habla que seguramente sentirán un miedo aterrador en otro futuro embarazo.

\section{Se habla en el grupo:}

- De la posibilidad de nuevos embarazos. Comentamos sobre la posibilidad de poder diferenciar cada embarazo, poder imaginarse al futuro bebé y poder proyectar, de forma que la experiencia pasada no lo ocupe todo.

- De poder esperar, ante un nuevo embarazo, algo diferente a un miedo aterrador. Hablamos de que el miedo aterrador pone el foco en la experiencia pasada. Se construye entre todos el que seguro que va a haber inquietud, momentos de temor, pero que si podemos diferenciar, podremos vivir el nuevo embarazo sin desbordarnos.

- Se recuerda también el mayor seguimiento que se va a tener por parte de los profesionales (como embarazo de riesgo) y también la posibilidad de atención psicológica.

- G: Comenta que ella ha recaído, que tiene miedo a ponerse enferma y también a que su hijo se ponga enfermo. No se atreve aún a acercarse a ver si ya están los resultados y tiene miedo a lo que 
puedan decirle. Tiene que ir ella sola a por los resultados. Todas las malas noticias de las ecografías, también las ha recibido sola. Dice que su marido está trabajando, tiene un puesto de responsabilidad "y no puede perder".

- D: Todo lo contrario. Tiene necesidad de saber. Quiere tener toda la información. También está hipocondríaca y sobreprotectora con su hija. Su madre la acompañaba siempre porque su marido también está trabajando. Se sentía mal de cargar a su madre con esa preocupación y culpable de hacer a su madre partícipe de su disgusto. A su marido ella le suavizaba las cosas para que no lo pasara mal. Su madre le decía que necesitaba estar con ella en esos momentos.

- R: De la gente que quiero, yo no me perdería ni lo malo ni lo bueno. Su madre también quiso estar en su parto, sabiendo lo difícil que era.

Hablamos de poder compartir. Aunque idealmente podríamos desear poder compartir todo con nuestra pareja, si no es posible, podemos buscar otros apoyos. No sentirnos solos en experiencias tan difíciles nos puede ayudar a encajarlo mejor y poder tolerar, sin derrumbarnos con lo que nos está pasando.

- C: Se encuentra bastante tranquila. Ya tiene momentos malos, pero no días malos. Se toma de otra manera los comentarios. Ha comprendido que su pareja expresa sus sentimientos con enfado, no con tristeza como ella, que es su forma de reaccionar, le comprende más y se siente menos sola. Entre los dos, sacan poco el tema para no preocuparse el uno al otro. Los dos tienen ganas de un nuevo embarazo. A él le ha ayudado mucho la vuelta al trabajo. Se han sentido muy queridos por amigos y familia.

- D: Comenta que su hijo le hace muchas preguntas sobre el bebé, si en el cielo juega, si tienen amigos, si se enfada... ella ya le contesta tranquila, sin angustia. Dice que lo va afrontando.

Hablamos de lo que hoy nos llevamos del grupo:

- M: Se lleva la alegría de R y su vestido de colores.

- C: Ver mejor al resto le ayuda mucho.

- R: También se reconforta mucho de ver a los demás avanzar. No se siente sola.

- C: Nunca se va a olvidar de este niño, pero quiere continuar su proyecto de familia, va dando pasos adelante.

- D: Dice que igual que uno necesita ayuda cuando hace una mudanza, también necesitamos a otros para mudar el estado de ánimo y que el grupo le ayuda a eso.

Quinta sesión. Comienzan varias pacientes comentando que están recibiendo resultados de anatomía patológica, autopsia, diferentes estudios... También coinciden varias de ellas que cuando se acercan determinadas fechas se ponen peor: los días de cada mes que se produjo la pérdida, o que les dieron noticias, o que sería la fecha prevista de parto. Alguna se tiene que incorporar al trabajo y otra cuenta que ya se ha ido su madre, por lo que se queda sola en casa. Vuelve a salir el tema de los comentarios que hace la gente, como si el bebé no hubiera existido o como si lo tuvieras que querer menos por haber durado pocos días.

- R: Yo siento que he sido madre, que he tenido dos hijos, aunque me haya pasado esta desgracia.

- A: Intenta que le afecte menos lo que dice la gente. Lo importante es lo que ella siente.

- G: Ella es muy rencorosa, y ha puesto una cruz a quien no está a la altura.

- R: Se ha tatuado el nombre de sus dos hijos.

- Varios también se han tatuado algo o desean hacerlo, como recuerdo de sus hijos. Hablan de querer así llevarlos siempre consigo.

Hablamos de respetar estas decisiones, pero que lo que siempre vamos a poder llevar todos es el recuerdo y la experiencia de lo que hemos vivido.

- G: Cuenta que si tiene otra hija, su niño quiere ponerle de nombre María, como a la bebé que murió. Dice que eso le hace pensar que no ha pasado duelo ni nada. Él tiene cinco años. Cuando vino a verla al hospital, ella intentó estar bien. Nunca la ha visto llorar. El padre le dijo al principio que no había nacido. Ella sí cree que le dijo que estaba muerta, en el cielo. No lo recuerda bien. Su hijo está muy apegado a ella y le cuesta separarse. 
- D: Nunca ha utilizado la palabra muerte, ya que cuando volvió a casa desde el hospital, su hijo estaba muy contento de verla y no le parecía el momento. Luego ya le dijo que se había tenido que ir al cielo, para siempre.

Hablamos de la dificultad que tenemos para utilizar la palabra muerte. Los niños están familiarizados con la muerte, lo ven en dibujos animados, películas... Captan la emoción de la familia. Podemos explicar lo ocurrido de acuerdo a la edad, transmitir la idea de irreversibilidad. Poder acompañar a los hijos, desde la verdad, es una mejor forma de protección.

Sexta sesión. Comienzan varios contando que han estado tranquilos, sin angustia, que echan de menos a sus bebés, pero que poco a poco van retomando sus cosas, su vida...

- D: Cuenta que estaba mejor, pero que había estado con mucha rabia por un comentario de la profe de su hijo... Le dijo también que estaba cuidando a su hijo como al bebé que había perdido, sobreprotegiéndolo. Comenta que se descolocó y se sintió muy mal desde esa tutoría.

- G: Ya se ha incorporado al trabajo. Ha tenido momentos de todo. No ha dado muchas explicaciones. Estuvo dando vueltas a si estaba o no preparada para incorporarse, pero al final se atrevió a afrontarlo.

- B: Sigue aún de baja y todavía no se ha planteado un nuevo embarazo, pero ya llora menos, le apetece estar con gente y tiene el dolor más controlado. Dice que su marido también está tranquilo y que él, desde el principio, lo ha tenido todo más claro.

- A: El fin de semana se han hecho cargo de su sobrina. Ya ha desaparecido el rechazo a las otras mamás. Las ve ya con normalidad, está tranquila y está más feliz. Dice que se da cuenta de que ella ha perdido dos hijos, sus padres dos nietos y sus hermanos dos sobrinos... Que seguramente no sabrían cómo ayudarla porque también tenían su pena.

Aparecen en el grupo algunos aspectos positivos de esta experiencia:

- G: Se ha dado cuenta de lo que realmente es importante en la vida. Valora más lo que quiere y lo que tiene. Como quiere ser madre, va a volver a intentarlo. Ahora se ve con más fuerza para seguir adelante.

- B: También ve la vida de otra manera. Le apetece comprender más a la gente, ser más generosa, ayudar a otros. Se ha decidido a colaborar con varias asociaciones. No quiere abandonar su proyecto de ser madre. Se ve ahora con más capacidad de no sentir envidia.

- M: Le ha permitido saber lo que es ser mamá... querer a alguien por encima de todo. Ahora es plenamente consciente de que quiere ser madre. Su marido y ella se han unido más. Su marido añade que se han conocido más entre ellos y que aún les quedan unos meses para intentarlo de nuevo. Ella dice que antes de esto quería tener todo bajo control. Ahora ha aprendido que hay cosas que no están al alcance de su mano y eso le libera. Cree que ha madurado.

- B: Cuenta que, cuando se quedó embarazada, no tenía instinto maternal. Ahora sí quiere vivir esa experiencia, pero desea una recompensa feliz. Aún tiene miedo. Su marido comenta que él y su mujer siempre han estado unidos, pero que ahora tienen un vínculo más fuerte. De esta experiencia se lleva las conversaciones con ella y los buenos amigos.

- A: Ha dejado de mirar por internet y está contenta de haberlo conseguido. Esta experiencia les ha permitido a ellos darse más cuenta del cariño que se tienen y que tienen muchas personas que les apoyan. Ha descubierto que pueden hacer frente al dolor y conoce nuevas fortalezas que no sabía, y otras que creía que tenía y no las tiene. Dice que ha cambiado su forma de pensar, no de ser. Su marido añade que él ha mejorado la capacidad de empatizar, solidarizarse, darse cuenta de lo que les pasa a los otros. Ella dice que al principio le costaba hablar en el grupo, pero que ha aprendido a comunicarse.

- C: Se lleva darse cuenta de todos los que te quieren y también de la fortaleza que tiene. Había cosas que antes le importaban y ahora no. Se complica menos en general.

- N: Le cuesta sacar algo en positivo. Su pareja y ella están más unidos y está más fuerte. Le cuesta saber que no van a tener la opción de tener más hijos, pero que el poder tener eso claro ya es algo positivo, porque el no saber la angustiaba mucho. Comenta que al principio era reacia a venir. Ahora lo considera muy positivo. Ha podido hablar de todo sin sentirse juzgada. 
- D: Se ha enriquecido con el grupo. También ha ido elaborando ella cosas aparte, aunque ha tenido que tomar medicación, que le han pautado en atención primaria. No tiene otro espacio para poder hablar y agradece haber tenido este espacio. Cuando acabe el grupo quiere buscar un psicoterapeuta.

- Marido de B: Comenta que ha podido afrontar temores.

- Marido de R: Le ha valido ver que cada uno piensa diferente y que no estás solo. Dice, puedes ponerte en la piel de otros a los que les pasa algo parecido.

- M: quiere confesar que antes de conocernos pensaba, "mal de muchos..." ahora ve que el grupo alivia, que no es de ser tonto, sino de comprensión, de comprender y sentirte comprendido.

\section{Séptima sesión:}

- C: Comenta que está embarazada. Se ha quedado a la primera. Los dos están muy contentos. Se lo han dicho a su otra hija. Comenta que en casa su marido y ella hablan de las cosas que se comentan en el grupo y que eso les ayuda mucho. En el grupo ha podido hablar sin problemas de lo que siente y ha estado muy a gusto.

- G: Tiene días de todo. Cuenta que no tiene fotos de su niño, pero sí una ecografía en 3D. Tenía mucha necesidad de ver la imagen y como no la encontraba se angustió, revolvió toda la casa y entró en bucle. Llamó a su madre y ella la ayudó. Aun así, cree que está mejor, que fue algo puntual. Se sintió impotente por no haberlo podido controlar, pero que luego ya lo pudo pensar y se tranquilizó.

- El marido de B. dice que ella ha sentido mucho no poder venir. Ha ido a una entrevista de trabajo. También fueron a la cita con la ginecóloga que fue encantadora con ellos. Fue la que ayudó a nacer a los bebés. Les comentó que, en principio, los bebés estaban sanos, que había sido una incompetencia del cuello del útero, y que lo van a intentar con un sólo bebé y un cerclaje preventivo. Podrán intentarlo en dos o tres meses.

\section{Hablamos de:}

Es diferente describir que compartir. En el grupo, hemos podido compartir nuestra experiencia y nuestros sentimientos.

Poco a poco podemos ir tolerando sentimientos de angustia, sin desbordarnos. Tenemos que calibrar el nivel que cada uno podemos tolerar, y poder pedir ayuda.

Carta de despedida para la última sesión, voluntaria.

\section{Octava y última sesión:}

- R: Cuenta que ha estado seis horas tatuándose. Le ha dolido mucho, pero está satisfecha.

- El marido de C.: También se ha hecho 2 rayas en los brazos.

- A N y L: También se les ha pasado por la cabeza.

Hablamos de qué quieren conseguir con los tatuajes, y de que no tiene porqué ser una necesidad para todos. Con poder pensar y recordar, puede ser suficiente.

- R: Quiero llevarlos en la piel, tocarlos. Para ella representa la belleza de haberlos tenido. Más que un tatuaje, son sus bebés. Le gusta mucho cómo han quedado.

- C: Dice que también quería hacerlo visible y que su pareja lo ha entendido.

- D: Comenta que cada uno tiene su forma particular de hacer un homenaje. Dice que en España no tenemos una palabra para definir a los padres que han perdido un hijo (sí hay huérfano, viuda) y que estar con otros que sienten como nosotros, cura.

- A: Sigue con las cenizas en casa. No ha querido despedirse.

Leen los escritos de despedida:

- Soltar el dolor o dejarte ir. Sí, soltar el dolor y transformarlo en amor. Tener su recuerdo en el corazón. Prometo disfrutar de la vida. Rendirse no es una opción. Te acompañaremos hasta el final.

- Te voy a recordar siempre con felicidad y amor. Estarás siempre conmigo, aunque de manera diferente. Me he perdonado. Estoy contenta con la decisión tomada. 
- Tomaron la decisión más dolorosa. Sienten no haberse despedido de su cuerpecito, de eso piden perdón, pero ahora lo han aceptado. Él les ha enseñado muchas cosas y se sienten orgullosos. No cambiarían por nada sus sensaciones y experiencia. Siempre vivirás presente entre nosotros. Te echaremos de menos, cariño. Te amamos.

\section{Hablamos de:}

Poder mantener un hilo que nos une, pero que también deja marchar.

Sentirnos unidos como parte de un ciclo de la vida en el que estamos todos, es algo que puede reconfortarnos y nos puede ayudar a tolerar la muerte de un hijo.

Nos despedimos.

\section{Conclusiones}

"Si se estrechan las manos, si se abraza..

es que la forma posible de estar juntos

es una despedida larga, clara.

Y que lo más seguro es el adiós”. Pedro Salinas

Compartir de forma tan íntima las emociones y la experiencia del duelo en un grupo de padres potencia de forma global las capacidades individuales de elaboración del mismo, favorece la unión de la pareja y actúa de forma preventiva frente a nuevos embarazos, siendo una opción privilegiada para la intervención en el duelo perinatal.

\section{Referencias}

Álvarez, M., Claramunt, M. A., Carrascosa, L. G. y Silvente, C. (2012). Las voces olvidadas. Pérdidas gestacionales tempranas. Santa Cruz de Tenerife, España: OB STARE.

Athey, J. y Spielvogel, A. M. (2000). Risk factors and interventions for psychological sequelae in women after miscarriage. Primary Care Update for Ob Gyns, 7, 64- 69.

Bayés, R. (2001). Psicología del sufrimiento y de la muerte. Barcelona, España: Martínez Roca.

Beutel, M., Will, H., Völkl, K., Von Rad, M. y Weiner, H. (1995). Entwicklung und Erfassung von Trauer am Beispiel des Verlustes einer Schwangerschaft: Die Miinchner Trauerskala (MTS). Psychotherapie Psychosomatik Medizinische Psychologie, 45, 295-302.

Bleichmar, H. (abril, 1999). Fundamentos y aplicaciones del enfoque modular transformacional. Aperturas Psicoanalíticas: revista internacional de psicoanálisis. Recuperado de https://aperturas.org/articulo.php?articulo $=0000052$

Bleichmar, H. (julio, 2003). Algunos subtipos de depresión, sus interrelaciones y consecuencias para el tratamiento psicoanalítico. Aperturas Psicoanalíticas: revista internacional de psicoanálisis. Recuperado de https://aperturas.org/articulo.php?articulo=0000245.

Bleichmar, H. (julio, 2010a). Una reformulación del duelopatológico: múltiples tipos y enfoques terapéuticos. Aperturas Psicoanalíticas: revista internacional de psicoanálisis. Recuperado de https://aperturas.org/articulo.php?articulo=647

Bleichmar, H. (2010 b). ¿Son todas las psicoterapias psicoanalíticas iguales? Clínica Contemporánea, 1(1), 5-17. https://doi.org/10.5093/cc2010v1n1a2

Bowlby, J. (1961). Processes of mourning [Procesos de duelo]. International Journal of Psychoanalysis, 42, 317-340.

Bowlby, J. (1980). Loss. Nueva York, Estados Unidos: Basic Books.

Bowlby, J. (1993). El apego. El apego y la pérdida I. Barcelona, España: Paidós Ibérica. 
Brier, N. (2008). Grief following miscarriage: a comprehensive review of the literature. Journal of Women's Health, 17(3), 451-464. https://doi.org/10.1089/jwh.2007.0505

Cabodevilla, I. (2007). Las pérdidas y sus duelos. Anales del Sistema Sanitario de Navarra, 30 (Supl. 3), 163176.

Campbell, H. E., Kurinczuk, J. J., Heazell, A. E. P., Leal J., Rivero-Arias, O. (2018). Healthcare and wider societal implications of stillbirth: a population-based cost-of-illness study. BJOG An International Journal of Obstetrics and Gynaecology, 125, 108-17. https://doi.org/10.1111/1471-0528.14972

Cassidy, P. (2013). Posicionamiento acerca de la infradeclaración y fiabilidad de las estadísticas de muertes perinatales en España. Recuperado de http://www.umamanita.es/wp-content/uploads/2015/06/Posicionamiento-acerca-de-la-infradeclaracion-y-fiabilidad-de-las-estadisticas-de-muertes-perinatales-en-Espania. pdf

Cassidy, P. (junio, 2018). Estadísticas y tasas de la mortalidad intrauterina, neonatal y perinatal en España. Revista muerte y duelo perinatal, 4, 23-34. Recuperado en http://www.umamanita.es/wp-content/ uploads/2018/06/2018-Cassidy-Estadisticas-y-tasas-de-mortalidad-intrauterina-neonatal-y-perinatal-en-Espana.pdf

Cirera, L., Martínez, C., Salmerón, D. y Navarro C. (2008). Subcertificación de las muertes perinatales en obstetricia y neonatología. Anales de Pediatría, 69(2), 129-133.

Côté-Arsenault, D. y Denney-Koelsch, E. (2011). "My Baby Is a Person": Parents' Experiences with Life-Threatening Fetal Diagnosis. Journal of Palliative Medicine, 14(12), 1302-1308. https://doi.org/10.1089/ jpm.2011.0165

Chitrit, Y. et al. (1999). Perinatal mortality in twin pregnancies: a 3 year analysis in Seine Saint-Denise (France). European Journal of Obstetrics and Gynecology Reproductive Biology, 86, 23-28.

De Bernis, L., Kinney, M. V., Stones, W., ten Hoope-Bender, P., Vivio, D., Leisher, S. H., ... Lawn, J. E. (2016). Stillbirths: Ending pre-ventable deaths by 2030. Lancet, 387, 703-16. https://doi.org/10.1016/ S0140-6736(15)00954-X

Dio Bleichmar, E. (2009). Apuntes sobre clínica de la adopción. Aperturas Psicoanalíticas: revista internacional de psicoanálisis. Recuperado de http://www.aperturas.org/articulo.php?articulo=0000587.

Doka, K. (Ed.). (2002). Disenfranchised grief. New directions, challenges and strategies for practice. Champaing, Estados Unidos: Research Press.

Flenady, V., Wojcieszek, A. M., Middleton P., Ellwood D., Erwich, J..J., Coory M., ... Goldenberg, R. L. (2016). Stillbirths: Recall to action in high-income countries. Lancet, 387, 691-702. https://doi.org/10.1016/ S0140-6736(15)01020-X

Freud, S. (1993). Duelo y Melancolía. En Obras Completas (Vol. XIV, pp. 235-255). Buenos Aires, Argentina: Amorrortu Editores. (Obra original publicada en 1917).

Garriga, C. (mayo, 2009). El lugar de la maternidad en las subjetividades de las mujeres. Más allá del destino biológico. El papel de la violencia de género. Recuperado de http://personal.ilimit.cat/cgarriga/articles/ XER_200909_MADRES.pdf

Instituto Nacional de Estadística (2017). Indicadores demográficos básicos. Indicadores de mortalidad infantil. Recuperado de http://www.ine.es/jaxiT3/Tabla.htm?t=1698\&L=0

Juri, L. (2006). Duelos intersubjetivos: el duelo segregado de Charles Darwin. Aperturas Psicoanalíticas: revista internacional de psicoanálisis. Recuperado de https://aperturas.org/articulo.php?articulo=0000403\&a=Duelos-intersubjetivos-el-duelo-segregadode-Charles-Darwin

Heazell, A. E. P., Siassakos, D., Blencowe, H., Burden, C., Bhutta, Z. A., Cacciatore, J.,... Downe, S. (2016). Stillbirths: Economic and psychosocial consequences. Lancet, 387, 604-16. https://doi.org/ 10.1016/S01406736(15)00836-3

Klein, M. (1989). El duelo y su relación con los estados maniaco-depresivos. En Obras Completas (Vol. I, pp. 346-371). Barcelona, España: Paidós. (Obra original publicada en 1940).

Kofman, Sh. e Imber, R. (2005). Pregnancy. En S. Feig, What do mothers want? Developmental Perspectives, Clinical Challenges. Hillsdale, Estados Unidos: The Analytic Press.

Kowalski, K. (1987). Perinatal loss and bereavement. En L. Sonstegard, K. Kowalski, B. Jennings (Eds.), 
Women's health. Vol 3: Crisis and Illness in Childbearing (pp. 25-42). Nueva York, Estados Unidos: Grune and Stratton.

Kowalski, K. (2001). Perinatal loss and bereavement. En K. R. Simpson y P. A. Creehan (Eds.), Perinatal nursing (pp. 476-491). Philadelphia, Estados Unidos: Lippincott Williams \& Wilkins.

Kübler-Ross, E. (1969). On death and dying. Nueva York, Estados Unidos: The Macmillan Company.

Lartigue, T., Maldonado-Durán, J. M., González-Pacheco, I., Sauceda-García, J. (2008). Depresión en la etapa perinatal. Perinatología y Reproducción Humana, 22, 111-131.

Lindemann, E. (1944). Symptomalogy and management of acute grief. American Journal of Psychiatry, 101, 141-148.

Lombardía, J. y Fernández, M. (2007). Ginecología y Obstetricia: manual de consulta rápida (2ª ed.). Madrid, España: Médica Panamericana.

López, A. P. (2011). Duelo perinatal: un secreto dentro de un misterio. Revista de la Asociación Española de Neuropsiquiatría, 31(109), 53-70.

Lovell, A. (2001). Changing identities of miscarriage and stillbirth. Influences on practice and ritual. Bereavement Care, 20,37-40.

Mistry, H., Heazell, A. E. P., Vincent, O., Roberts, T. (2013). A structured review and exploration of the healthcare costs associated with stillbirth and a subsequent pregnancy in England and Wales. BMC Pregnancy Childbirth, 13. https://doi.org/10.1186/1471-2393-13-236

Montesinos, A., Román, N. A., Muñoz, M., Elías, B. L. (2013). Asistencia al duelo neonatal: diez años de experiencia en una Unidad de Neonatología. Revista Chilena de Pediatría, 84(6), 650-658. Recuperado de http://www.scielo.cl/pdf/rcp/v84n6/art08.pdf

Moscarello, R. (1989). Perinatal bereavement support service: three-year review. Journal of Palliative Care, $5,12-8$.

Neugebauer, R., Kline, J., O’Connor, P., Shrout, P., Johnson, J., Skodol, A., Wicks, J. y Susser, M. (1992). Determinants of depressive symptoms in the early weeks after miscarriage. American Journal of Public Health, 82, 1332-1339.

Pastor Montero, S. M., Vacas Jaén, A. G., Rodríguez Tirado, M. B., Macías Bedoya, J. M. y Pozo Pérez, F. (2007). Experiencias y vivencias de los padres y profesionales ante la pérdida perinatal. Revista Paraninfo, 1. Recuperado de http://www.umamanita.es/wp-content/uploads/2015/06/2007-Pastor-Montero-Experiencias-y-vivencias-de-los-padres-y-profesionales-ante-la-perdida-perinatal.pdf

Pastor Montero, S. M., Romero-Sánchez J. M., Hueso-Montoro, C., Lillo-Crespo, M., Vacas-Jaén, A. G., Rodríguez-Tirado, M. B. (2011). La vivencia de la pérdida perinatal desde la perspectiva de los profesionales de la salud. Revista Latinoamericana de Enfermería, 19. https://doi.org/10.1590/S0104-11692011000600018

Pastor Montero, S. M.(2016). Abordaje de la pérdida perinatal. Un enfoque desde la investigación acción participativa (Tesis doctoral). Universidad de Alicante, España. Recuperada de http://hdl.handle.net/10045/54551

Payás, A. (2007). Intervención grupal en duelo. Duelo en Oncología. Sociedad española de oncología médica (SEOM). Disponible en: https://seom.org/seomcms/images/stories/recursos/sociosyprofs/documentacion/ manuales/duelo/duelo14.pdf

Payás, A. (2010). Las tareas del duelo: Psicoterapia de duelo desde un modelo integrativo relacional. Barcelona, España: Paidós Ibérica.

Payás, A. (2014). El mensaje de las lágrimas: una guía para superar la pérdida de un ser querido. Barcelona, España: Paidós Ibérica.

Rando, T. A. (1983). An investigation of grief and adaptation in parents whose children have died from cancer. Journal of Pediatric Psychology, 8, 3-20.

Rando, T. A. (1984). Grief, Dying, and Death: Clinical Interventions for Caregivers.Champaign, Estados Unidos: Research Press Company.

Robert, M. y Silver, M. D. (2007). Fetal death. Obstetric and Ginecology, 109(1), 153-167. Recuperado de http://www.utilis.net/Morning\%20Topics/Obstetrics/Fetal\%20Death.pdf

Santos, P., Yáñez, A. y Al-Adib, M. (2015). Atención profesional a la pérdida y del duelo durante la maternidad. Consejería de Salud y Política Sociosanitaria. Servicio Extremeño de Salud. Gobierno de Extremadura. 
Recuperado de https://www.elpartoesnuestro.es/sites/default/files/recursos/documents/libro_duelo_ses.pdf Sociedad Española de Ginecología y Obstetricia. (SEGO). (2011a). Aborto espontáneo. Progresos de Obstetricia y Ginecología, 54(4), 207-224. https://doi: 10.1016/j.pog.2010.10.008

Sociedad Española de Ginecología y Obstetricia. (SEGO). (2011b). Actuación psicosomática en las pérdidas fetales y perinatales. Progresos de Obstetricia y Ginecología, 54(3), 148-156. https://doi.org/ 10.1016/j. pog.2010.10.007

Steen, S. E. Perinatal death: bereavement interventions used by US and Spanish nurses and midwives (2015). International Journal of Palliative Nursing, 21, 79-86. https://doi.org/10.12968/ijpn.2015.21.2.79

Tizón, J.L. (2004). Pérdida, pena, duelo: vivencias, investigación y asistencia. Barcelona, España: Paidós Ibérica.

Tizón, J. L. y Sforza, M. G. (2008). Días de duelo: encontrando salidas. Barcelona, España: Alba Editorial.

Utrilla, M. (1998). ¿Son posibles las terapias en Instituciones?: Estudio situacional. Madrid, España: Biblioteca Nueva.

World Health Organization. (WHO). (2006). Neonatal and perinatal mortality: country, regional and global estimates. Ginebra, Suiza: WHO.

Worden, J. W. (1982). Grief counseling and grief therapy: A handbook for the mental health practitioner. Nueva York, Estados Unidos: Springer Publishing Company.

Worden, J. W. (2004). El tratamiento del duelo: asesoramiento psicológico y terapia (2 ${ }^{\mathrm{a}}$ Ed.). Barcelona, España: Paidós Ibérica.

Artículo recibido: $11 / 10 / 2018$

Artículo aceptado: 22/10/2018 